\section{THREE CASES OF THROMBOSIS OF THE LATERAL SINUS}

BY J. WALKER WOOD, L.R.C.P. \& S. EdIN., L.F.P.S. GLASG.,

FORYERLY HOUSE SURGEON, CENTRAL LONDON THROAT AND EAR HOSPITAI.

TaE following three cases occurred during my recent term of office at the Central London Throat and Ear Hospital, and were all under the care of Dr. Percy Jakins, to whom I am indebted for permission to publish them.

Thrombosis of the lateral sinus is one of the complications of middle-ear suppuration that practitioners always have to be on the look-out for. It may show itself as a perfectly clear clinical picture presenting no great difficulties of diagnosis, or, again, should it be masked by signs and symptoms of some other intracranial complication, such as meningitis or brain abscess, it may be a very difficult task to decide the exact lesion with which you have to deal. Haseler's figures show that in 81,684 cases of chronic middle-ear suppuration 116 deaths took place from intracranial complications, and of these 48 were due to thrombosis, 40 to meningitis, and 28 to brain abscess. Figures obtained from the hospitals of London by Pitt show an almost exactly similar proportion. Thus it is evident that thrombosis of the lateral sinus is one of the most frequent, if not the most frequent, complications of a supparating ear. When the prevalence of chronic suppurative catarrh and the proximity of the lateral sinus to the mastoid antrum (for the antrum is always involved in chronic suppurative catarrh, if not the prime cause of persistence of suppuration in the ear) are considered-it may be the sinus forming one of the antral walls-it is surprising that thrombosis is not more common than it is. I can recall several cases when on opening the mastoid the sinus was found lving bare in the posterior wall of the antrum, covered with granulations and exposed to absolute direct infection. When thrombosis does take place the infection is brought about more frequently through intercommunicating venous channels than by direct extension. This is quite easily understood when the great resisting power of the dura is considered-a resisting power much greater than that of bone; the presence of granulations on the dura in some cases is in reality an additional protection against infection of the sinus.

In all cases of chronic middle-ear suppuration the surgeon ought ever to be on the qui vive for symptoms which indicate intracranial trouble. Patients should be warned of the dangers which they run; urgent symptoms should be explained to them, as headache, vomiting, giddiness, shivering fits, mastoid pain, \&c. In addition they ought to be impressed with the necessity of immediately reporting themselves to the aural surgeon should one or all of these symptoms become evident. The onset and symptoms of thrombosis are more easily explained by a consideration of the following cases.

CASE 1 - The patient, a male, aged 14 years, was on Sept. 6th, 1909, admitted to the Central London Throat and Far Hospital with a history of a discharge from the right ear of three months' duration. The discharge ceased suddenly a week previously to admission, and two days later the lad complained of severe pain in the head. The"pain was located principallv behind the right ear, and was very severe and constant. Since the discharge ceased the patient had had several rigors. There was marked tenderness in the occipital region over the site of the mastoid emissary vein (Griesinger's symptom) and along the line of the internal jugular vein. The head was bent over on to the right shoulder and supported with the patient's right hand. There was no mastoid swelling or tenderness. The temperature was $100.8^{\circ} \mathrm{F}$, and the palse 120, small and weak. Shortly after admission the patient had a severe rigor, the temperature rising to 1040. The tongue was coated and furred. The pupils were equal and active and the discs normal. There was no nystagmus, nor was there rombergism. and the reflexes were normal. D pnamometer : right hand, 50 ; left, 40 . There was no vomiting or nausea, and consciousness was clear and unimpaired. The right meatus was full of inspissated pus and no view of membrane was obtained. A diagnosis was made of thrombosis of the lateral sinus

Operation.-On Sept. 6th the right mastoid was exposed by the usual incision behind the ear. The mastoid cells were opened and were found to contain pus. The antrum also contained pus and cholesteatoma. The bridge and ossicles were removed. The lateral sinus was next exposed, and as soon as the bony wall was broken through pus welled up into the wound (peri-sinus abscess). The sinus contained a large whitish clot, very offensive, not broken down but firmly adherent. The clot was partially removed with spoon and curette (but not until fluid blood was reached), and the sinus was plugged with iodoform gauze. At this point there was troublesome hæmorrhage from the mastoid emissary vein. The upper flap, which had been cut previously, was stitched into place, a large rubber tube was inserted in the meatus and partial closing of the post-auricular wound completed the operation.

A pathological report of the pus by Dr. Wyatt Wingrave stated that it contained almost every variety of known organisms with the exception of the tubercle bacillus, the predominating ones being the streptococcus, the staphylococcus, the bacillus proteus vulgaris, and the bacillus pyogenes fotidus.

On Sept. 7th the patient's condition had improved slightly. The temperature was subnormal, and the pulse was 78 and very irregular. Vomiting and rigors were absent. There was slight head retraction. Kernig's sign was present but not marked. When the wound was dressed the discharge was principally blood-stained serum. On the 8th the patient's general condition had greatly improved and the pulse was more regular. There was a slight rise of temperature at 2 P.M., but no rigor. The head retraction had disappeared. The urine contained a trace of albumin. The wound was dressed. The discharge was very fœtid, and on this account a dressing of chlorinated soda was used; the plug in the lateral sinus was also changed. On the 9 th the general condition remained good, the pulse being 86 and the temperature $98^{\circ}$. The tongue was coated, but there was no sickness or nausea, and no rigors or headache. There was now no pain on pressure over the internal jugular vein. From the 10 th to the 21 st there was steady convalescence. The wound was dressed daily, being sponged out with hydrogen peroxide and plugged with plain sterile gauze. The patient was allowed to get up on this day. On Oct. 11th he was sent home. The wound had healed, but there was a slight discharge through the meatal canal. On March 7th, 1910, the discharge had quite ceased and the hearing was good.

This was a fairly typical case of thrombosis of the lateral sinus. The following are the main points of importance:(1) Cessation of discharge; (2) sudden onset of pain behind the ear; (3) tenderness along the internal jugular vein ; (4) shivering (rigors); (5) Griesinger's symptom (tenderness and slight odema over the site of the emissary vein, although no tenderness or swelling over the mastoid antrum); (6) the discs normal; and (7) consciousness unimpaired.

The next case illustrates well the difficulties of diagnosis. From the history, the examination of the patient, and the lumbar puncture, a diagnosis of meningitis was quite justified.

CASE 2.-The patient, a married woman, aged 28 years, was sent by Dr. J. Read Pooler to the Central London Throat and Ear Hospital to be placed under the care of Dr. Percy Jakins on Dec. 28th, 1909. There had been discharge from the left ear all her life, increasing during the last three weeks. A week before admission there had been a sudden onset of high temperature, ranging from $101^{\circ}$ to $103^{\circ} \mathrm{F}$., accompanied by a dull, drowsy condition, with head retraction and severe frontal and occipital headache. There was occipital pain radiating down the spine, with marked tenderness in the region of the occiput and over the site of the mastoid emissary vein on the left side. The slightest movement of the head caused severe pain. The patient could be roused to answer a question, but would immediately lapse into a dull, drowsy condition. The face was alternately fiushed and pale. The temperature was $100^{\circ}$ and the pulse was 100 and irregular. There was obstructive deafness. The meatus was full of inspissated pus; no view of membrane obtained. The tongue was coated and furred. There was no paresis of the ocular muscles or nystagmus, and the pupils reacted to light and accommodation. Slight optic neuritis was present on both sides. The knee-jerks were sluggish, the left one being almost absent. There was ankle clonus on both sides, most marked on the left side. Dorsiflexion on both sides; Kernig's sign present. Lumbar puncture was performed, and 15 cubic centimetres of fluid were 
extracted under Iow pressure. Cells present included polymorphonuclear leucocytes 80 per cent., lymphocytes 20 per cent. Bacteria present were bacillus proteus vulgaris, bacillus pyogenes foetidus. A culture from the cerebro-spinal fluid showed the same bacteria. An examination of the aural discharge revealed the presence of the bacillus proteus vulgaris, the bacillus pyogenes foetidus, and staphylococci. There was ro sickness, or rigors, or giddiness. A diagnosis of meningitis was made, and it was decided to explore the mastoid.

Operation.-On Dec. 29th the radical mastoid operation was performed by Dr. Percy Jakins. The bridge contained a large cell which was full of pus. A large quantity of pus was also found in the antrum. The lateral sinus was completely thrombosed, and an abscess was found between it and the bone, communicating with an extra-dural abscess in the posterior fossa. Another extra-dural abscess was found above the tegmen antri, which was carious. The dura of the middle and posterior fossæ was carefully examined, but no opening was found. In the course of the operation the external semicircular canal was obliterated. The wound being very fotid it was dressed with chlorinated soda and hydrogen peroxide, the post-auricular wound being plugged and left open. Towards the end of the operation, whilst on the operating-table, the patient had a severe rigor. On the 30 th another severe rigor was experienced and the temperature rose to $105^{\circ}$. The patient was very dull and drowsy and the pulse and respirations were rapid. On Jan. 1st, 1910, the temperature was somewhat pyæmic in type. Lumbar puncture was performed, but no fluid could be got out. On the 3rd the patient's condition was about the same. She could be roused to answer a question, but otherwise she remained in a semicomatose condition. She had less pain than on admission, and the deafness was less marked. There was a tendency to left-sided facial paralysis. The wound, in spite of daily dressings, was still very foetid, and the tendency of the temperature was to go up. On the 4th the pus from the wound was examined and was found to contain staphylococci, streptococci, the bacillus protens vulgaris, and the bacillus pyogenes fœtidus. The patient's general condition showed slight improvement. The temperature varied from $100^{\circ}$ to $101^{\circ}$. On the 5 th the general condition was about the same. The patient expressed herself as feeling much better. The temperature varied, but the tendency was to keep up. On the 6th the general condition was not so good. The patient complained of headaches and was much duller, and had slight head retraction. The discs were examined again, and the edges were found to be very indistinct. There was marked engorgement of the veins, especially in the right eye; the temperature was still up. On the 15 th the temperature gradually became normal and then sub-normal, the pulse remaining rapid. Consciousness became quite clear and the patient's condition was greatly improved. The wound was granulating well, but was discharging freely. On the 17th the temperature was subnormal, with a rapid pulse. The tendency to left-sided facial paralysis was more marked. There were paresis of the left external rectus and marked ankle-clonus, especially on the left side. The left knee-jerk was more active than the right. The left-hand grip was weaker than the right. Giddiness was experienced on sitting up in bed and was rotatory in type, objects appearing to go to the right. There was slight spontaneous nystagmus to the right side. Associated movements could be performed as well on the left as on the right side. There was extreme somnolence, but the patient could always be roused. On the 23rd the patient remained in the same condition, with a sub. normal temperature and a rapid pulse, and she complained of headache. The reflexes and the nystagmus were as on the 17th. The patient had vomited twice. The amount of discharge from the wound varied-one dressing would be saturated with discharge, while another would be quite dry. On the 24 th the headache had become very severe. Otherwise the patient's condition was unaltered. The giddiness was much less. On the 25th the headache was very severe and was referred principally to the frontal and occipital regions. The vomiting continued. The patient was very dull and sleepy, with a temperature of $97 \cdot 8^{\circ}$ and a pulse-rate of 100. The reflexes were the same as a week ago. An examination of the optic discs revealed a large flame-shaped hæmorrhage on the right side. On account of the headache and the vomiting, and the state of the pulse and temperature, Dr. Jakins decicled to explore the temporo-sphenoidal lobe. On the 27th a second operation was performed. The old wound was opened up, an incision was carried up vertically behind the ear, and the periosteum was elevated. A trephine opening was made half an inch directly above the meatus and the middle fossa was opened. The meninges appeared to be quite normal. The dura was incised. The temporo-sphenoidal lobe was explored with the "pus-seeker," but no abscess was found. A small fistula was iound in the tegmen antri ; this was well opened up. On the 28th, following upon the operation, the patient was very dull and collapsed, the temperature being $96^{\circ}$ and the pulse 40 . She was semi-conscious, cold, and in a condition of extreme shock, with feeble, irregular pulse and dilated pupils. Brandy, strychnine hypodermically, hot water bottles, and hot saline enemata were freely used. She remained in this condition for two days, when, suddenly becoming fully conscious, alert, and brisk, she desired to sit up in bed to read, and was able to answer any questions intelligently. The sudden change in the condition of the patient was associated with an increased discharge of pus from the mastoid wound. The slight paresis of the face and eye had improved, and the wound was granulating well. On the 31st Dr. Purves Stewart kindly saw the case with Dr. Jakins. He could find no local lesion, only general meningitis. The wound granulated well and the patient made an uninterrupted recovery, leaving the hospital with the wound closed on Feb. 28th, the facial and ocular paralyses having entirely disappeared. When seen on March 12th the patient appeared to be in splendid condition. She had been staying at Bournemouth for 14 days and had not had, she said, a headache since the last operation.

How far the diagnosis was at fault will be readily seen from the subsequent history of the case as narrated above. Meningitis was present, but in addition there was a completely thrombosed sinus, a peri-sinous abscess and an extradural abscess. The points in favour of meningitis were: (1) continuous high fever and no rigors until after the operation; (2) the dull and drowsy condition of the patient; (3) the head retraction with pain on movement; (4) the lumbar puncture; and (5) optic neuritis.

During the further progress of the case several points suggested either an extra-dural abscess or a brain abscess. They were: sub-normal temperature and pulse; the ocular paresis; the condition of the reflexes; headache and vomiting; bæmorrhage into the left optic disc; and the variable amount of discharge from the mastoid wound. The giddiness and nystagmus were most likely due to a localised labyrinthitis caused by an injury to the labyrinth during the first operation. The absence of rigors with a totally blocked sinus is worthy of note.

The last case is a further instance of diagnostic difficulties.

CASE 3. - The patient, a male, aged $4 \frac{1}{2}$ years, was sent to hospital by Dr. G. Thomson of Ealing. The boy had been operated upon at another hospital for tonsils and adenoids. Fourteen days later the maxillary glands on the right side of the neck commenced to swell and eventually they broke down, forming an abscess, which was opened. During the following week both ears began to discharge. The patient was on June 1st, 1909, admitted to the Central London Throat and Ear Hospital under the care of Dr. Jakins. He was evidently in great pain and was extremely restless. The face was drawn and pinched, and the cheeks were flushed. The temperature was $100^{\circ} \mathrm{F}$, and the pulse was 120 and irregular. There was profuse discharge from both ears, with some tenderness of the right mastoid, but no swelling or redness. A large mass of broken down glands in the neck was still discharging freely. There had been no rigors or sickness. Consciousness was quite clear, but the child complained of pain in and behind the right ear.

Operation.-Cortical mastoid right. A post-auricular incision was carried down into the neck to include the old incision made for the abscess. The bone was soft and carious. The antrum when opened was found to contain pus under pressure; the lateral sinus was exposed and was found to be completely thrombosed with granulations all round. As the thrombus consisted of a bealtby clot it was not removed, nor were the granulations over the sinus curetted. The bridge was not removed. The wound in the neck was laid freely open and the glands were well scraped. The whole wound was then plugged and left open. On June 2 nd the $t \in m p \in$ rature was r.sing, and the patient was still very restless and in pain. His 
general condition remained the same. The wound when dressed discharged freely. Ankle clonus was present on both sides. On the 3rd the temperature was oscillating and the pulse was rapid and irregular, but there were no rigors. The discs were normal. On the 10 th there were no rigors but great oscillations of temperature, an evening rise to $103^{\circ}$ or more, falling in the morning to normal. The patient complained of headache and of pain in the left ear, but there was no sickness. The chest was examined with a negative result. On the 12th a second operation was performed, Dr. Jakins deciding to explore the left mastoid. The usual incision behind the ear was made and the bone was exposed. The antrum was opened and was found to contain pus under pressure, the surrounding bone being soft and carious and easily removable with a sharp spoon. The lateral sinus was not exposed. The wound was plugged and left open. There was a rise of temperature in the evening to $104^{\circ}$. On the 13th the temperature was still remittent in type but there were no rigors. There was slight head retraction. The patient complained greatly of headache, which was principally accipital. There was no impairment of consciousness. on the foregoing symptoms it was decided to investigate the condition of both sinuses. A third operation was performed on the 14th. The sinus of the right side was first examined and was found to be perfectly patent, although only a fortnight previously it was completely thrombosed. After plugging the right wound the left sinus was investigated, and as its wall appeared to be healthy and as it pulsated freely it was not interfered with. There was great sickness for several hours after the operation with subnormal temperature and pulse. On the 16 th the sickness continued, but with no rigors, and there were profuse and marked perspirations, which were limited to the head. Tache cérébrale was well marked ; Kernig's sign was present. Ankle clonus was present on the left side. The knee-jerks were inactive and the urine contained a trace of albumin. The child was perfectly conscious and bright. From the 17th to the 27 th the temperature continued to oscillate, the oscillations gradually getting less. The lungs were again examined with negative results. The temperature slowly sank to normal. On July 1st the temperature was normal and both wounds had practically healed. The patient now returned home. When seen on Dec. 28th the boy was found to have gained greatly in weight and the hearing on both sides was normal. He looked the picture of health.

The principal points here are: (1) the remittent temperature with free perspiration, but absence of rigors ; (2) the headache and sickness; (3) the absence of optic neuritis; (4) the presence of Kernig's sign, but no symptom of meningitis beyond this; and (5) the absence of Griesinger's symptom.

In conclusion, I should like to point out that in none of these cases was the internal jugular vein tied. Should rigors continue after opening the lateral sinus and the removal of clot, whether septic or not, then, and not before, is the time to ligature the vein.

Devonshire-street, $\mathrm{W}$

\section{THE TREATMENT OF CHOLERA ASIATICA WITH AN ANTI-ENDOTOXIC SERUM.} BY R. TANNER HEWLETT, M.D. LOND., F.R.C.P. LOND., D.P.H.,

PROFESSOR OF GENERAL PATHOLOGY AND BACTERIOLOGY IN KING'S COLLEGE, LONDON; AND IJCTURER ON BACTERIOLOGY, LONDON SCHOOL OF 'TROPIGAL MEDICINE.

VARIOUS attempts have been made to prepare an anticholera serum for the treatment of cholera asiatica. Under ordinary conditions the cholera vibrio produces little or no toxin, and an anti-microbic serum prepared by immunisation with caltures has been found to be of no practical value.

Some years ago Metchnikoff, Roux, and Salimbeni ${ }^{1}$ found that by cultivating the cholera vibrio in a medium consisting of a gelatine-salt-peptone mixture a feeble extracellular toxin is formed. With this toxin horses were immunised and the serum obtained was proved to possess immunising and curative properties experimentally when tested on young suckling rabbits which were found to be

1 Annales de l'Institut Pasteur, vol. x., 1896, p. 257. See also Salimbeni in Bactériothérapie. Vaccination, et Sérotbérapie (J. B. Baillière et Flls, Paris, 1909), p. 347. susceptible to infection with the cholera vibrio. In the epidemic of cholera in Russia last year Salimbeni ${ }^{2}$ employed this serum and considers that it is undoubtedly of value. The dose was 50-100 c.c. administered intravenously in salt solution (150-500 c.c.)

Bran and Denier ${ }^{2}$ also obtained a cholera toxin by the use of a medium consisting of horse serum with an addition of 10 per cent. defibrinated horse blood.

The late Dr. Allan Macfadyen ${ }^{4}$ found that by the trituration of cholera cultures in the presence of liquid air the intracellular cholera juice or "cholera endotoxin" possessed decided toxic properties and by the immunisation of animals an anti-endotoxic serum was obtained which possessed considerable protective power as well as agglutinative and bacteriolytic properties. Through the kindness of $\mathbf{M r}$. Wellcome I was able last year, at the Wellcome Physiological Research Laboratories, to immunise a horse by the Macfadyen method with cholera endotoxin prepared by the trituration of virulent cholera cultures obtained through Dr. Haffkine from India.

This anti-endotoxic serum experimentally possessed considerable protective and curative powers tested on guineapigs. Thus 0.0001 c.c. and 0.5 c.c. of serum protected against 10 and 50 lethal doses respectively of living cholera culture injected simultaneously intraperitoneally into guineapigs. Curatively 1 c.c. of the serum saved the life of a guinea-pig inoculated intraperitoneally with four lethal doses of living cholera culture six and a half hours previously.

Through the kindness and interest of Madame Sieber, of the Imperial Institute of Experimental Medicine at St. Petersburg, a trial of this serum was made on nine cases of cholera which occurred during the epidemic of last year in Russia. The patients were in the Obuchar Hospital, St. Petersburg, under the care of Dr. Stüblern, and I am indebted to him for notes of the cases and for permission to publish them. The following is a record of the cases (a verbatim translation of Dr. Stühlern's notes) :-

CASE 1.-Cabinet-maker, alcoholic subject, aged 40 years. Suffered from premonitory symptoms for a fortnight, then acute onset, with crom premonitory symptoms for a fortnight, then acute onset, with commencement of the attack. 3 litres of 0.7 per cent. salt solution with $50 \mathrm{c} \mathrm{c}$. of serum given intravenously $\left(42^{\circ} \mathrm{C}\right.$.) together with wh 50 c c. of serum given intravenously $\left(42^{\circ} \mathrm{C}\right.$.), together with first infun first infusion. 200 c.c. nf salt solution with 25 c.c. of serum, shbcutaneously. Third influsion, 24 hours after the second infusion. 300 c.c. of salt solution infusion produced decided improvement. The patient recovered. Case 2.-Goldsmith, alcoholic subject, aged 48 years. Acute onset, with pulsus parrus, vox choleraica, cramps, and cyanosis. First inf asion, 18 hours after the commencement of the attack. 3 litres 0 salt solution with 50 c.c. of serum intravenously, togetber with $200 \mathrm{c.C}$ of salt solution with 25 c.c. of serum subcutaneously. Second infusion six hours after the first infusion. 2.5 litres of salt solution wlth $25 \mathrm{ccc}$ of serum intravenously. Third infusion (time not stated). 300 c.c. of salt solution with 25 c.c of serum subcutaneously. Fourth infusion (time not stated). 2 litres of salt solution with 25 c.c. of serum intravenously. The patient passed into a comatose typhidid condition developed facial erysipelas, and died on the sixth day of the disease. CASE 3.-Agricultural labourer (Erdarbeiter), aged 28 years. Acut onset, pulseless, with cyanosis, vox choleraica, and cramps. First infusion, 20 hours after the commencement of the attack. 3 litres 0 salt solution with $50 \mathrm{c}$.c. of serum intravenously, together with $100 \mathrm{c.c}$ of salt solution with 25 c.c. of serum subeutaneously. Second infusion six hours after the first infusion. 25 litres of salt solution with $50 \mathrm{c.c}$ of serum intravenously. Third infusion (time not stated). 150 c.c. of salt solution with 25 c.c. of serum subcutaneously. The patient recovered.

CASE 4.-Cabinet-maker, aged 33 years. After premonitory diarrhcea lasting for 48 bours the cholera at tack commenced, with cyanosis and small pulse. First infusion, 20 hours after the commencement of the attack. 2.5 litres of salt solution with 50 c.c. of serum intravenously, together with 150 c.c. of salt solution with 25 c.c. of serum subcutaneously (hæmorrhagic fæces). Second infusion (time not stated). 3 litres of salt solution with caffeine (no serum) intravenously. The patient died on the sever

CASE 5.-Waiter, aged 26 years. Cholera Rcutissima, First infusion, eight hours after the commencement of the attack. 3 litres of salt solution with 25 e.c. of serum intravenously, together with 25 c.e of serum subcutaneously. Second infusion, seven hours after the first infusion. 3 litres of salt solution with 25 c.c. of serum intravenously, together with 25 c.c. of serum subcutaneously. Third infusion, 12 hours after the secold infusion. $2 \cdot 5$ litres of salt solution with caffeine (no serum) intravenously. Fourth infusion, 12 hours after the third serum) intravenously. Fourth infusion, 12 hours after the third together with 25 c.c. of serum subcutaneously. The patient died (time not stated). Hamorrhagic enteritis was present.

not stated). Habemorrhagic enteritis was present.
CASE 6.-Labourer, aged 20 years. The attack commenced 12 hours CASE 6 .- Labourer, aged 20 years. The attack commenced 12 hours
after premonitory symptoms. The patient was pulseless at the commencement of the treatment. First infusion, 12 hours after the commencement of the attack. 3 litres of salt solution with 25 c.c. of serum intravenously, together with 25 c.c. of serum subcutaneously.

2 Annales de l'Institut Pasteur, vol. xxiv., 1910, p. 34 3 Ibid., vol. $\mathrm{xx}, 1906$. 4 THE LANCET, 1906, vol. ii.,p. 494 . Also "The Cell as the Unit of
Life" (J. and A. Churchill, 1908). 